\title{
RESEARCH
}

Open Access

\section{Maternal blood folate status during early pregnancy and occurrence of autism spectrum disorder in offspring: a study of 62 serum biomarkers}

Olga Egorova ${ }^{*^{*}}$ (D), Robin Myte ${ }^{2}$, Jörn Schneede ${ }^{3}$, Bruno Hägglöf ${ }^{4}$, Sven Bölte ${ }^{5,6,7}$, Erik Domellöf ${ }^{8}$, Barbro Ivars A'roch ${ }^{4}$, Fredrik Elgh ${ }^{9}$, Per Magne Ueland ${ }^{10,11}$ and Sven-Arne Silfverdal ${ }^{1}$

\begin{abstract}
Background: Autism spectrum disorder (ASD) evolves from an interplay between genetic and environmental factors during prenatal development. Since identifying maternal biomarkers associated with ASD risk in offspring during early pregnancy might result in new strategies for intervention, we investigated maternal metabolic biomarkers in relation to occurrence of ASD in offspring using both univariate logistic regression and multivariate network analysis.

Methods: Serum samples from 100 women with an offspring diagnosed with ASD and 100 matched control women with typically developing offspring were collected at week 14 of pregnancy. Concentrations of 62 metabolic biomarkers were determined, including amino acids, vitamins ( $, B, D, E$, and $K$ ), and biomarkers related to folate (vitamin $B_{9}$ ) metabolism, lifestyle factors, as well as C-reactive protein (CRP), the kynurenine-tryptophan ratio (KTR), and neopterin as markers of inflammation and immune activation.

Results: We found weak evidence for a positive association between higher maternal serum concentrations of folate and increased occurrence of ASD (OR per 1 SD increase: 1.70, 95\% Cl 1.22-2.37, FDR adjusted $P=0.07$ ). Multivariate network analysis confirmed expected internal biochemical relations between the biomarkers. Neither inflammation markers nor vitamin $\mathrm{D}_{3}$ levels, all hypothesized to be involved in ASD etiology, displayed associations with ASD occurrence in the offspring.

Conclusions: Our findings suggest that high maternal serum folate status during early pregnancy may be associated with the occurrence of ASD in offspring. No inference about physiological mechanisms behind this observation can be made at the present time because blood folate levels may have complex relations with nutritional intake, the cellular folate status and status of other B-vitamins. Therefore, further investigations, which may clarify the potential role and mechanisms of maternal blood folate status in ASD risk and the interplay with other potential risk factors, in larger materials are warranted.
\end{abstract}

Keywords: Autism, Pregnancy, One-carbon metabolism, Folate, Vitamin B, Vitamin D, Vitamin A, Inflammation

\footnotetext{
* Correspondence: o_yegorova@yahoo.com

'Department of Clinical Sciences, Pediatrics, Umeå University, Umeå, Sweden

Full list of author information is available at the end of the article
}

(c) The Author(s). 2020 Open Access This article is distributed under the terms of the Creative Commons Attribution 4.0 International License (http://creativecommons.org/licenses/by/4.0/), which permits unrestricted use, distribution, and reproduction in any medium, provided you give appropriate credit to the original author(s) and the source, provide a link to the Creative Commons license, and indicate if changes were made. The Creative Commons Public Domain Dedication waiver (http://creativecommons.org/publicdomain/zero/1.0/) applies to the data made available in this article, unless otherwise stated. 


\section{Background}

Autism spectrum disorder (ASD) is a developmental condition characterized by social communication and interaction challenges alongside with repetitive, stereotypic, restricted interests, and behaviors causing different levels of disability [1]. Over the last two decades, the prevalence of ASD has increased considerably and is now estimated to be $1-3 \%$ in high-income countries [24]. A plethora of factors are discussed as an explanation for this trend, among them changes in the diagnostic criteria, increased awareness and access to care, improved services, but also changes in environmental conditions, micronutrient status, and maternal lifestyle [5-7]. Genome sequencing data indicate hundreds of potential ASD risk genes, both rare and common variants [7-9]. Further, the systemic and central nervous system physiology of ASD suggests a possible role of oxidative stress, neuroinflammation, and mitochondrial alterations that are likely to be influenced by gene-environment interactions $[10,11]$. In individuals with a genetic predisposition, a range of environmental factors have been proposed to increase ASD risk [7, 12]. Among them are variations in maternal metabolism at pregnancy $[13,14]$. Beside maternal metabolism, adverse health conditions during early pregnancy such as viral infections, inflammation, and immune activation are considered as risk factors for psychiatric disorders in the offspring [15-19]. Environmental factors may act via epigenetic mechanisms that are potentially modifiable and preventable [20]; therefore, the understanding of such risk factors may indicate a path to reduce incidence of ASD onset.

Previous studies were usually limited to one or two metabolic factors such as body-mass index and result of maternal diet and fatty acid metabolism [21-23], smoking [24] vitamin D [25-34] and folate supplementation [35-43], paracetamol [44, 45], valproic acid, thalidomide, and antidepressants [13, 46, 47], and phthalates [48]. Maternal defects in one-carbon metabolism have also been proposed to influence ASD risk [49-52]. So far, however, no single factor has been identified to play a leading role in the development of ASD [53-55], giving support to the notion that autism has a complex and multifactorial origin [56].

In the present paper, we investigate a comprehensive panel of 62 serum biomarkers related to one-carbon metabolism, inflammation, and life-style and fat-soluble vitamins in first-trimester maternal blood samples. To the best of our knowledge, there are no previous studies that have simultaneously investigated a large spectrum of metabolic markers in maternal blood in relation to ASD risk in the offspring. Based on published literature, our primary hypothesis was that low maternal folate and vitamin D status and increased levels of markers of inflammation and immune activation such as C-reactive protein (CRP), neopterin, and a higher kynureninetryptophan ratio (KTR) might be associated with increased risk of ASD in the offspring.

The potential impact of vitamin D on ASD onset has been discussed extensively during the last two decades $[12,57,58]$. Connection between vitamin D and ASD onset give facts that individuals with ASD have been observed to suffer from vitamin D deficiencies [59-62], and vitamin $D$ supplementation may improve their socio-psychological status [63, 64]. Highest fraction of children with ASD are born in the end of the summer, that menaces that mothers had relatively lower vitamin $\mathrm{D}$ levels at the first and second trimester of pregnancy [65]. Numerous studies associate low vitamin D status and/or lack vitamin $\mathrm{D}$ formation and supplementation during pregnancy with an elevated risk of ASD in offspring in Sweden [32-34] and world-wide [25-29, 31]. In animals, vitamin $\mathrm{D}$ insufficiency leads to aberrant brain development and autism-resembling behavior [66]. The ability of vitamin D to downregulate substances associated with a risk of ASD occurrence, such as free radicals and heavy metals [67] and neurologically harmful cytokines [68], to increase cellular levels of the antioxidant glutathione [69] and its association with the ability of the brain to recover after damage [70] connects vitamin D deficiency with a possibility of increased risk of ASD onset. ASD is supposed to be an inflammationconnected disorder [18], with elevated cytokine levels in the patients' blood [71-73], altered mononuclear cell activation [74, 75], astrocyte activation, and neuroinflammation [76-80]. Vitamin D has an anti-inflammatory activity [81-83], downregulates inflammation both in immune and nervous systems [84], and normalizes macrophage activity in peripheral blood in persons with ASD [85]. Even direct influence of vitamin D on gene expression cannot be ruled out as receptors for vitamin $\mathrm{D}$ are broadly expressed throughout developing brain tissue [86] and are known to regulate the synthesis of many proteins involved in mammalian brain development $[87,88]$.

Folate is a collective term for folic acid derivatives. Pre-, periconceptional and first trimester pregnancy folic acid supplementation is successfully used to prevent neural tube defects [89]. Folate is transported into the cell by proton-coupled folate transporter, reduced folate carrier 1 and folate receptors (FRs). Four folate receptors have been discovered until now. The folate receptor subclass 1 (FR1), also named FR $\alpha$, is expressed during development in placental, choroid, and neural plate cells. Mouse embryos homozygote for the knock-out FR $\alpha$ gene develop neural-tube defects and die before birth [90]. Folate is involved in transmission of one-carbon groups and thus synthesis of amino acids, nucleotides, neurotransmitters synthesis, nuclear acids, and proteins. 
Folate-dependent homocysteine remethylation connects folate with the transsulfuration pathway [91, 92]. Beside its metabolic function, folate also has a direct influence on immune system modulation [93, 94] and on gene expression regulation through $\mathrm{FR} \alpha[95,96]$. In such way, the alteration of cell folate levels may trigger the onset of ASD through numerous processes in the developing brain from DNA synthesis and cell proliferation to neurotransmitters and other cell signal molecule synthesis, lipid synthesis, membrane formation, and myelination. Maternal folate levels during pregnancy may even cause onset of ASD in children through immune system modulation. More than a decade ago, it was suggested that folic acid use by the mothers could been one of the factors that increase the risk of ASD in children [97], an observation confirmed by some [42, 43, 96, 98] but rejected by other $[35-39,98]$ studies. It is important, therefore, to explore the question further.

The sensitive period for ASD onset in humans is yet not determined. As ASD is known to be accompanied by a modified brain structure and connectivity $[99,100]$, the risk for ASD is associated mostly with unfavorable events in the second and third trimester of pregnancy when the connections between neurons establish [100, 101]. However, there are suggestions that alterations in fetal brain development at the end of the first-beginning of the second trimester of pregnancy, a window of neuron production and migration inside the developing brain, may also cause ASD onset $[13,102]$ Therefore, we consider it possible to use the pre-diagnostic maternal blood samples collected during week 14 of pregnancy for our study.

\section{Methods and material Study population}

Children born in Västerbotten County, northern Sweden, with mothers who had been residing in Sweden during the whole pregnancy period were eligible for the study. A total of 393 children with an ICD-10 based ASD diagnosis, born between 1996 and 2009 (Fig. 1 and Table 1), were identified from medical records from the Child and Adolescent Psychiatric Clinic in Västerbotten County. The diagnostic procedure followed standards from Child Neuropsychiatric specialized teams mainly working in Child and Adolescent Psychiatry clinics and Child rehabilitation centers. The diagnostic process included medical history, current and past symptomatology, and functional abilities according to parent and teacher interviews as well as rating scales, child observation data, and psychological and medical tests. Children were diagnosed according to DSM-IV [1] and met the ICD-10 criteria for F 84.0 (Infantile autism), or F 84.5 (Asperger syndrome). Permission for using stored prediagnostic blood samples was granted from 201 women with an offspring diagnosed with ASD (Fig. 1). From the population register of Västerbotten County, 400 typically developing children, born between the years 1996 to 2009 , were identified and asked to participate in the study, and 147 mothers granted permission to use blood samples (Fig. 1). Because the present investigation was novel and feasibility of the sample material for analysis of the proposed biomarkers had not been tested before, the biobanks steering committee gave access to serum samples from only 100 pregnant women who gave birth

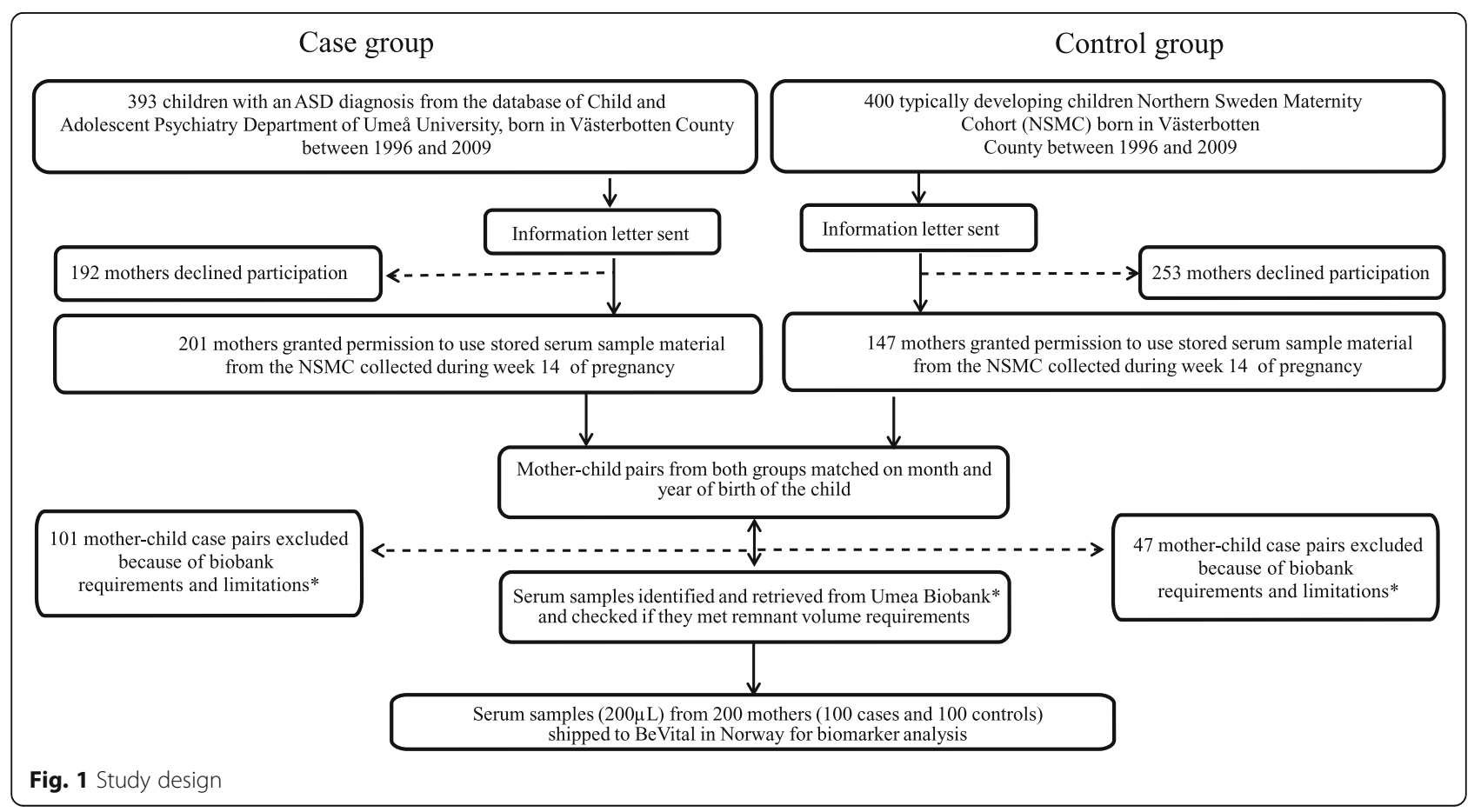


Table 1 Baseline characteristics

\begin{tabular}{|c|c|c|c|c|c|}
\hline & \multicolumn{2}{|c|}{ Cases $(n=100)$} & \multicolumn{2}{|c|}{ Controls $(n=100)$} & \multirow[b]{2}{*}{$P^{\mathrm{b}}$} \\
\hline & $\bar{n}$ & Median $\left(I Q R^{a}\right)$ or $\%$ & $\bar{n}$ & Median (IQR) or $\%$ & \\
\hline Mother's age (years) & 100 & $31(28-34)$ & 100 & $30(26-33)$ & 0.02 \\
\hline Year of blood serum sampling & 100 & $2003(2001-2005)$ & 100 & 2002 (1999-2005) & 0.07 \\
\hline Month of birth, child & 100 & $7(4-10)$ & 100 & $8(4-10)$ & 0.50 \\
\hline Child sex, boy & 76 & $76 \%$ & 78 & $78 \%$ & 0.87 \\
\hline \multicolumn{6}{|l|}{ ASD diagnosis } \\
\hline Infantile autism (F84.0) & 74 & $74 \%$ & & & \\
\hline Asperger's syndrome (F84.5) & 26 & $26 \%$ & & & \\
\hline
\end{tabular}

Interquartile range (IQR), 25-75th percentile

${ }^{\mathrm{b}}$ Test for difference with Mann-Whitney $U$ test (continuous variables) or Chi-square test (categorical variables)

to a child diagnosed subsequently with ASD (74 cases of infantile autism, and 26 cases with Asperger syndrome) and from 100 pregnant mothers giving birth to a typically developing child. Further requirements were that the remnant volume in sample tubes should be at least $700 \mu \mathrm{L}$ and that a maximum of $200 \mu \mathrm{L}$ serum could be used for the present project. Groups were matched by year and month of childbirth.

\section{Collection, storage of blood serum samples}

The serum samples used in this study were obtained from the Northern Sweden Maternity Cohort (NSMC) founded in 1975 [103]. The serum samples were routinely collected for testing of systemic infections and rubella IgG antibody titers at the first midwife visit at one of the more than 30 primary health care centers in Västerbotten County. The time point of the first visit is at the discretion of the patients and occurs in most cases between weeks 7 and 18 centering around week 14 [103, 104]. As we did not have access to the exact gestational age at blood sampling, we assigned all patients to week 14 [104]. Samples were exposed to room temperature and initial storage in refrigerators at $4{ }^{\circ} \mathrm{C}$ at the primary care centers for variable periods and periodically shipped, frozen, to a central repository at Umeå University Hospital, where they are analyzed and the leftovers were stored at $-20^{\circ} \mathrm{C}[103,104]$.

\section{Biochemical analyses}

Serum samples were analyzed at Bevital AS (Bergen, Norway) [105]. We analyzed a total of 62 biomarkers with focus on one-carbon metabolism including Bvitamins; lipid-soluble vitamins $\mathrm{A}, \mathrm{D}, \mathrm{E}$, and $\mathrm{K}$; markers of immune activation and inflammation such as CRP, KTR, and neopterin; and lifestyle factors (such as cotinine, a marker of nicotine exposure, and trigonelline, a marker of coffee consumption) (Additional file 4: Table S1). The different biomarkers were analyzed using liquid and gas chromatography-mass spectrometry methods
[106-108], immuno-MALDI-TOF mass spectrometry [109], and microbiological methods [110, 111]. Details on analytes stability, assay characteristics, analytical performance, and reference ranges can be found elsewhere [108, 111-116]. Most likely due to non-optimal initial storage conditions (see above), as well as the limited total sample volume not allowing for repeat analysis, 13 biomarkers (5-formyl-tetrahydrofolate, pyridoxal $5^{\prime}$ phosphate [vitamin B6], pyridoxine, thiamine, thiamine monophosphate [vitamin $\mathrm{B}_{3}$ ], 3-hydroxykynurenine, anthranilic acid, 3-hydroxyanthranilic acid, picolinic acid, $\alpha$-ketoglutaric acid, phylloquinone [vitamin K1], menaquinone-4 [vitamin $\mathrm{K}_{2}$ ], 25-hydroxyergocalciferol [25OH-vitamin $\left.\mathrm{D}_{2}\right]$ ) could only be quantified in a limited number of cases $(<10 \%$ of the total number of available serum samples) and were consequently excluded from further statistical analyses (Additional file 4: Table S1). Unmetabolized folic acid was detected in small amount of samples (17\%) and these samples were excluded from further statistical analyses of biomarkers because we assumed that that unmetabolized folic acid was an expression of higher folate exposure most likely due to high doses of supplemental folic acid. As there is no mandatory folic acid food fortification in Sweden and the majority of pregnancies are unplanned folic acid intake during early pregnancy might rather be an indicator of co-morbidities and not of natural periconceptional folic acid intake. In multivariate analyses, we further excluded methionine and acetamidobenzoylglutamate (determination was not possible in 41 and $33 \%$ of the samples, respectively). Cotinine, a marker of nicotine exposure, exhibits high storage stability [117]. We used serum concentrations $>85 \mathrm{nmol} / \mathrm{L}$, as cut-off for active smoking, a values below as an indicator of passive and non-smoking. We also calculated the kynurenine/tryptophan ratio (KTR) as a marker of immune activation [118]. By oxidation processes during storage 5-methyltetrahydropholate (mTHF) is partly converted into 4-alfahydroxy-5-methyl-tetrahydrofolate (hmTHF). Therefore, 
for the further statistical analysis, we used the parameter 'total folate' which is the sum of detected mTHF and hmTHF [111].

In total, 45 out of the tested 62 biomarkers could be identified in the present sample material and were included in the final statistical analyses (Additional file 4: Table S1, Fig. 4).

\section{Statistical analysis}

Mann-Whitney $U$ test or Chi-square tests were used to test for differences in baseline characteristics between cases and controls. Correlations between metabolites were calculated with Spearman's correlation coefficient on pair-wise complete observations.

Associations between serum biomarkers and ASD occurrence were estimated as odds ratios (ORs) per 1 standard deviation (SD) increase in biomarker concentrations using multivariable adjusted logistic regression. Estimates were adjusted for mother's age, sampling year, child gender, serum cotinine, and serum total folate (as a marker for overall folate metabolism status). Estimates for vitamin $\mathrm{D}$, the only biomarker showing seasonal differences (Additional file 2: Figure S2), were further adjusted according to half-year of blood sampling (April-September or October-March). $P$ values were corrected for multiple testing by controlling the false discovery rate (FDR) according to the Benjamini and Hochberg method [119]. To evaluate potential differences in association by ASD type, we also estimated type-specific ORs for infantile autism and Asperger's syndrome using multinomial logistic regression. Heterogeneity in association between the types was examined with Wald's test.

To account for complex interrelations between the biomarkers, we estimated undirected Bayesian networks using machine learning. A Bayesian network is a graphical representation of all relations among a set of variables, depicted as nodes and edges. Nodes represent the variables (here biomarkers) while edges represent conditional dependencies between variables. Bayesian network analysis allows simultaneous modeling of multiple dependencies between potential risk factors and disease. Bayesian network analysis can be considered as an appropriate means to study interactions and relative contributions between different above mentioned components of maternal metabolism during early pregnancy and ASD [120]. The network models were estimated on discrete data, with serum biomarkers dichotomized into low/high groups, below/ above the median of biomarker concentration distributions of the controls, and further included mother's age, sampling year, sampling month, and sex of child. Networks were estimated using the Hill-climbing algorithm in the bnlearn R-package in 1000 bootstrap samples drawn from the data set [121]. The final network was achieved by averaging over the bootstrap networks, where an independent association (i.e., an edge between two nodes) was included if it was present in a frequency above an estimated threshold [120]. Association strength between the variables in the network was measured by the frequencies of an independent association in networks present in the 1000 bootstrap samples (a measure between 0 , not present in any bootstrap network, and $100 \%$, present in all 1000 bootstrap networks).

All computations were conducted in $\mathrm{R}$ v. 3.4 .2 ( $\mathrm{R}$ Foundation for Statistical Computing, Vienna, Austria.). Network visualizations were made in Cytoscape v. 3.2.1. All tests were two-sided and $P$ values $<0.05$ were considered significant.

\section{Ethics}

The study was approved by the Regional Ethics Board at Umeå University, Sweden, 2013-06-18, Dnr 2013-66$31 \mathrm{M}$. Through an information letter, written informed consent was obtained, and mothers gave permission for using stored early pregnancy blood samples for the purpose of the present study, and for collecting registered information.

\section{Results}

\section{Baseline characteristics}

From the NSMC, we got access to a total of 100 blood samples from mothers with occurrence of ASD in offspring (case group) and 100 blood samples from the matched control group (Fig. 1). Baseline characteristics for cases and controls are presented in Table 1. The mothers of children later diagnosed with ASD were marginally older at the time of blood sampling compared to the mothers constituting the control group (31 vs. 30 years).

Unmetabolized folic acid was detected in a larger, however statistically insignificant, number of mothers in the case group compared to controls (22\% and $12 \%$ respectively, $P=0.09$ ) (Additional file 4: Table S1).

Serum vitamin D levels showed seasonal variations and were slightly higher in blood samples collected during the months from July to October (Additional file 2: Figure S2). No other biomarkers exhibited clear seasonal differences. For unknown reasons, several biomarkers differed markedly by sampling year, in particular before and after 2001 (Additional file 2: Figure S2). However, seasonal and year associations were preserved and essentially the same in cases and controls (Additional file 1: Figure S1 and Additional file 2: Figure S2).

Levels of kynurenine, kynurenic acid, and quinolinic acid were slightly higher in male pregnancies (approximately $10 \%$ higher concentrations compared to mothers pregnant with girls, $P=0.03,0.04$, and 0.06 , respectively). No other significant differences by sex of the offspring were observed. 
Spearman's correlations with a hierarchical cluster analysis between the serum biomarkers are presented in Fig. 2. Amino acids, such as lysine, serine, or glycine, showed strong, positive correlations. These amino acids were negatively correlated with B-vitamins (e.g., total folate and pyridoxal), and weakly positively associated with CRP. Vitamin D did not show strong associations with any of the markers (Fig. 2).

\section{Associations between biomarkers and ASD}

Adjusted ORs for ASD occurrence per 1 SD increase in biomarker levels are presented in Fig. 3. Higher early pregnancy total folate levels were associated with an increased probability of having a child with ASD (OR per 1 SD increase: $1.70,95 \%$ CI 1.22-2.37, $P=0.002$ ). Taking multiple testing into account, weak evidence remained (FDR adjusted $P=0.07$ ). No other biomarker showed any significant association with occurrence of ASD, including CRP (OR per 1 SD increase: 1.20, 95\%
CI $0.89-1.61, P=0.24)$, the kynurenine/tryptophan ratio (OR 0.91, 95\% CI 0.66-1.26, $P=0.58$ ), neopterin (OR per 1 SD $0.97,95 \% \mathrm{CI} 0.72-1.31, P=0.86$ ), and vitamin D levels (OR per 1 SD increase: $0.78,95 \%$ CI $0.58-1.08$, $P=0.11)$. Active smoking, defined as serum cotinine > $85 \mathrm{nmol} / \mathrm{l}$, was not associated with ASD risk in the present material (OR 1.21, 95\% CI 0.51-2.88, $P=0.66$ ). There was no significant difference in overall biomarker profile between cases and controls (Additional file 3: Figure S3). Risk estimates for the total folate-ASD association were similar for infantile autism and Asperger's syndrome (ORs 1.69 and 1.68, P-heterogeneity $=0.99$, Additional file 5: Table S2). No other biomarker displayed any clear difference in ASD association by type.

\section{Multivariate Bayesian network analysis}

The Bayesian network depicting independent associations between all biomarkers and background variables is presented in Fig. 4a. The associations among the

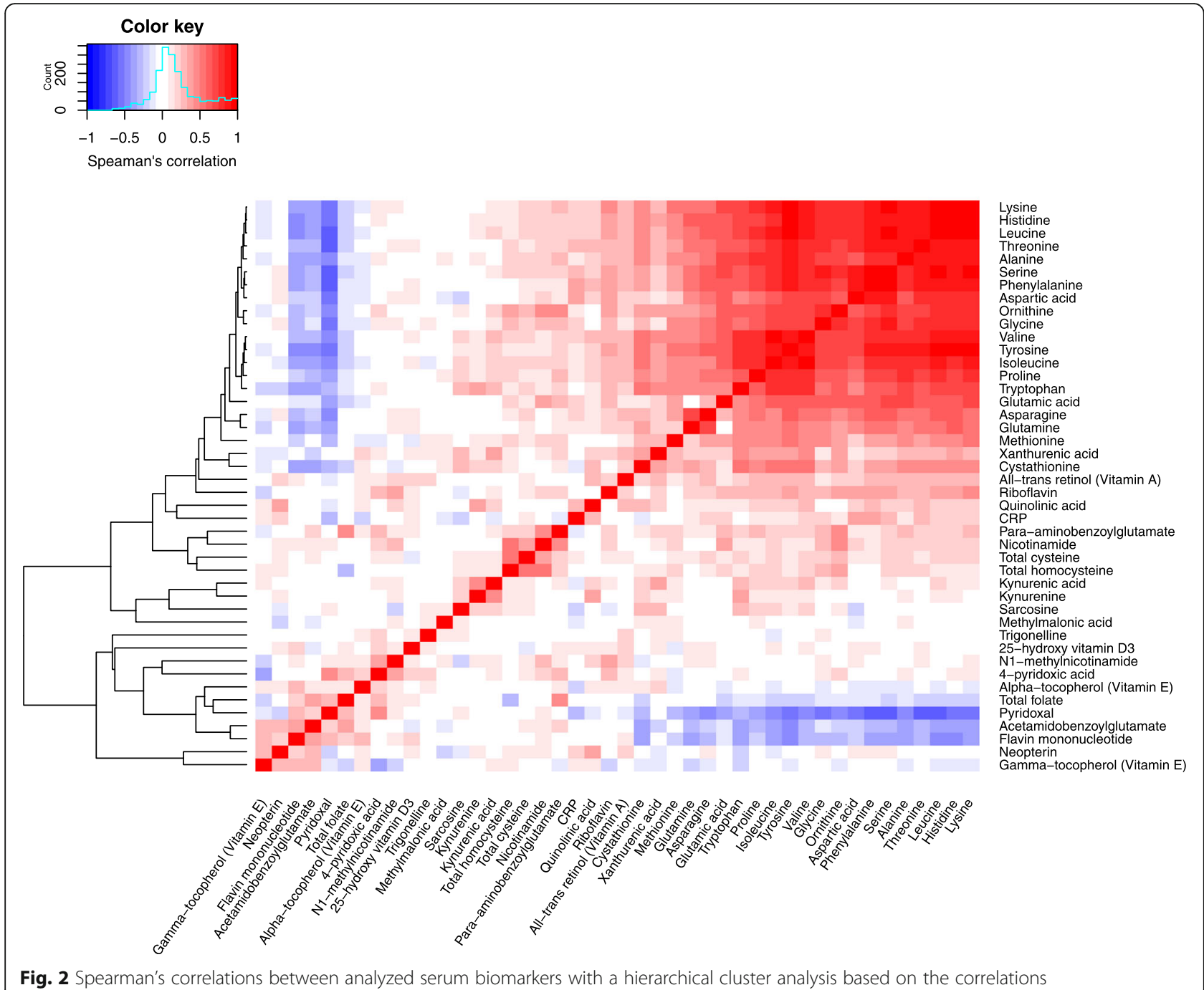




\begin{tabular}{|c|c|c|c|c|c|c|c|c|}
\hline Biomarker & Median cases & Median controls & OR & $95 \% \mathrm{Cl}$ & $\mathbf{P}$ & $\mathbf{P}$ adjusted & & \\
\hline Total folate & 12.9 & 10.7 & 1.70 & $1.22-2.37$ & 0.002 & 0.07 & & $\Rightarrow$ \\
\hline Acetamidobenzoylglutamate & 0.60 & 0.53 & 1.35 & $0.86-2.10$ & 0.19 & 0.89 & & $\rightarrow$ \\
\hline Glutamic acid & 478 & 461 & 1.27 & $0.92-1.73$ & 0.14 & 0.89 & & \\
\hline CRP & 3.1 & 2.5 & 1.22 & $0.90-1.64$ & 0.21 & 0.89 & & \\
\hline Total cysteine & 213 & 209 & 1.20 & $0.89-1.63$ & 0.22 & 0.89 & & \\
\hline Total homocysteine & 6.9 & 6.9 & 1.13 & $0.83-1.53$ & 0.45 & 0.97 & & \\
\hline Phenylalanine & 170 & 172 & 1.13 & $0.79-1.62$ & 0.51 & 0.97 & & \\
\hline Methylmalonic acid & 0.16 & 0.16 & 1.09 & $0.81-1.48$ & 0.58 & 0.97 & & 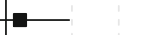 \\
\hline Alanine & 598 & 633 & 1.08 & $0.76-1.54$ & 0.67 & 0.97 & & \\
\hline Tryptophan & 87.9 & 89.3 & 1.08 & $0.76-1.52$ & 0.68 & 0.97 & & \\
\hline Serine & 337 & 347 & 1.08 & $0.75-1.56$ & 0.68 & 0.97 & & \\
\hline Glycine & 446 & 463 & 1.07 & $0.76-1.50$ & 0.70 & 0.97 & & \\
\hline Gamma-tocopherol (Vitamin E) & 1.7 & 1.7 & 1.04 & $0.75-1.43$ & 0.82 & 0.97 & & \\
\hline Lysine & 289 & 314 & 1.04 & $0.72-1.52$ & 0.82 & 0.97 & & \\
\hline Asparagine & 13.2 & 15.8 & 1.03 & $0.71-1.48$ & 0.89 & 0.97 & & \\
\hline Isoleucine & 96.5 & 102.7 & 1.02 & $0.72-1.45$ & 0.93 & 0.97 & & \\
\hline Nicotinamide & 263 & 272 & 1.01 & $0.75-1.35$ & 0.97 & 0.97 & & \\
\hline Kynurenine & 1.2 & 1.3 & 0.99 & $0.74-1.33$ & 0.95 & 0.97 & & \\
\hline Pyridoxal & 16.1 & 15.1 & 0.98 & $0.70-1.37$ & 0.91 & 0.97 & & \\
\hline All-trans retinol (Vitamin A) & 1.5 & 1.6 & 0.97 & $0.71-1.32$ & 0.84 & 0.97 & & \\
\hline Neopterin & 7.0 & 7.0 & 0.97 & $0.72-1.31$ & 0.86 & 0.97 & & \\
\hline Histidine & 139 & 155 & 0.97 & $0.64-1.47$ & 0.88 & 0.97 & & \\
\hline Methionine & 1.2 & 1.2 & 0.97 & $0.64-1.47$ & 0.89 & 0.97 & - & \\
\hline Leucine & 272 & 313 & 0.97 & $0.66-1.45$ & 0.90 & 0.97 & - & \\
\hline Aspartic acid & 193 & 201 & 0.95 & $0.68-1.32$ & 0.74 & 0.97 & & \\
\hline Threonine & 222 & 227 & 0.94 & $0.66-1.35$ & 0.74 & 0.97 & & \\
\hline Quinolinic acid & 347 & 346 & 0.93 & $0.69-1.24$ & 0.62 & 0.97 &  & \\
\hline Ornithine & 135 & 142 & 0.93 & $0.66-1.30$ & 0.66 & 0.97 & 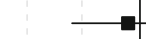 & \\
\hline Para-aminobenzoylglutamate & 0.87 & 0.86 & 0.93 & $0.66-1.32$ & 0.68 & 0.97 & $\longrightarrow$ & \\
\hline Tyrosine & 81.6 & 90.2 & 0.92 & $0.62-1.36$ & 0.67 & 0.97 & & \\
\hline Alpha-tocopherol (Vitamin E) & 18.1 & 18.9 & 0.91 & $0.67-1.22$ & 0.52 & 0.97 & & \\
\hline N1-methylnicotinamide & 118 & 121 & 0.90 & $0.67-1.21$ & 0.49 & 0.97 & $\longrightarrow$ & \\
\hline Valine & 327 & 347 & 0.90 & $0.64-1.28$ & 0.57 & 0.97 & $\longrightarrow$ & — \\
\hline Sarcosine & 0.77 & 0.84 & 0.88 & $0.65-1.18$ & 0.40 & 0.97 & $\longrightarrow$ & 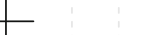 \\
\hline Proline & 285 & 293 & 0.88 & $0.64-1.22$ & 0.44 & 0.97 & $\longrightarrow$ & \\
\hline 4-pyridoxic acid & 18.6 & 18.2 & 0.87 & $0.63-1.19$ & 0.38 & 0.97 & 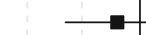 & \\
\hline Riboflavin & 41.8 & 41.6 & 0.84 & $0.62-1.13$ & 0.24 & 0.9 & $\longrightarrow$ & \\
\hline Cystathionine & 0.07 & 0.08 & 0.84 & $0.61-1.17$ & 0.31 & 0.97 & $\longrightarrow$ & \\
\hline Trigonelline & 0.26 & 0.31 & 0.78 & $0.56-1.10$ & 0.16 & 0.89 & $\longrightarrow$ & \\
\hline 25-hydroxy vitamin D3 & 60.9 & 66.6 & 0.77 & $0.57-1.04$ & 0.08 & 0.88 & $\longrightarrow$ & \\
\hline Xanthurenic acid & 31.2 & 35.2 & 0.77 & $0.56-1.05$ & 0.09 & 0.88 & $\longrightarrow$ & \\
\hline Glutamine & 58.7 & 83.0 & 0.77 & $0.52-1.16$ & 0.21 & 0.89 & $\longrightarrow$ & \\
\hline Kynurenic acid & 33.4 & 35.7 & 0.75 & $0.55-1.02$ & 0.06 & 0.88 & $\longrightarrow$ & \\
\hline \multirow[t]{2}{*}{ Flavin mononucleotide } & 7.8 & 8.1 & 0.71 & $0.47-1.07$ & 0.10 & 0.88 & $\longrightarrow$ & \\
\hline & & & & & & & $\begin{array}{l}0.50 \quad 0.70 \\
\text { OR per } 1.5\end{array}$ & $\begin{array}{lll}1.0 & 1.5 \quad 2.0 \\
\text { SD increase }\end{array}$ \\
\hline \multicolumn{9}{|c|}{$\begin{array}{l}\text { Fig. } 3 \text { Odds ratios (ORs) for ASD risk by } 1 \text { standard deviation (SD) increase in biomarkers levels. ORs were calculated using logistic regression } \\
\text { adjusted for mother's age at sampling, year of sampling, sex of child, and serum cotinine and } \mathrm{mTHF} \text { levels. Vitamin } \mathrm{D}_{3} \text { was further adjusted for } \\
\text { month of sampling (light/dark months). Median serum concentration levels in cases and controls are presented in nmol/L for biomarker } \\
\text { kynurenic acid; } 25 \text {-hydroxy vitamin } \mathrm{D}_{3} \text {; xanthurenic acid; trigonelline; cystathionine; 4-pyridoxic acid; quinolinic acid; pyridoxal; neopterin; nicotinic } \\
\text { acid; para-amino benzoylglutamate; acetamidobenzoglutamate; hmTHF; mTHF;and in mg/l for CRP and all remaining biomarkers }\end{array}$} \\
\hline
\end{tabular}

biomarkers illustrated in the network were largely in line with expected biochemical relations. For instance, the interconnectedness between circulating amino acids, associations between circulating metabolites in the kynurenine pathway (tryptophan, kynurenine, kynurenic acid, and xanthurenic acid), and the associations between coffee and smoking biomarkers trigonelline and cotinine. Independent associations between occurrence of ASD and all variables except for riboflavin and total folate were, however, generally weak (Fig. 4b), and did not reach the threshold for inclusion of $50 \%$.

\section{Discussion}

This case-control study with pre-diagnostic, first trimester maternal blood samples is the first of its kind to investigate a comprehensive panel of biomarkers reflecting vitamin status (including folate, and vitamin D), lifestyle (smoking and coffee consumption), and inflammation and immune activation (CRP, kynurenine, kynurenic acid, and quinolinic acid, KTR and neopterin) in relation to the occurrence of ASD in the offspring. The other characteristics of the present study is that biomarkers were analyzed in individual, pre-diagnostic maternal blood samples and not 





(See figure on previous page.)

Fig. 4 a Bayesian network of serum biomarkers and background information variables estimated by a Hill-climbing algorithm and averaged over 1000 bootstrap samples. A line between two variables indicates an association independent of all other variables in the network. Line thickness corresponds to association strength measured as proportion of times an association was present in 1000 bootstrap sample networks (a thicker line indicates a stronger association). Node size corresponds to the number of connections. The network was estimated using discrete data (with biomarkers divided into low/high groups, with cut-off defined by the median biomarker concentrations in the controls). b Association strengths to ASD risk for each biomarker measured as proportion of times an association was present in 1000 bootstrap sample networks

estimated based on register data or food frequency questionnaires [21-32, 35-46]. The majority of blood samples were taken at week 14, but ranged between week 7 and week 18 in the total cohort. Among cases, there was no indication of differences in the biomarker relationships between the ASD subtypes, infantile autism, and Asperger syndrome, indicating that results are probably valid across the autism spectrum and independent of IQ. In the entire sample, there were sex-dependent differences in tryptophan metabolism: kynurenine, kynurenic acid, and quinolinic acid were higher in serum of mothers pregnant with boys (approximately 10\% higher than in mothers pregnant with girls). Total maternal folate serum levels at pregnancy were positively associated with the occurrence of ASD in children, although the association lost significance when adjusted for other factors. There were no associations between maternal vitamin D, life-style, and markers of inflammation or immune activation with ASD occurrence in children. Despite non-optimal initial storage conditions of samples and failure to determine the concentrations of some unstable metabolites, mostly from the vitamin B group, multivariate Bayesian network analysis (Fig. 4a) showed an expected relationship between biomarkers that conform the validity of analyses [105]. The validity of the analytical results in the present study is strengthened by the fact that the majority of biomarkers were found within the expected concentration ranges and that the anticipated subtle seasonal variations for vitamin $\mathrm{D}$, folate, and CRP $[105,122]$ could be proved in our material.

Increased serum levels of kynurenine, kynurenic acid, and quinolinic acid were seen in mothers pregnant with boys both with and without ASD. These substances belong to the kynurenine pathway of tryptophan metabolism forming kynurenine that is further metabolized to kynurenic or quinolinic acid [123]. The sex difference cannot be explained simply by coincidental increased tryptophan consumption in male pregnancies, as male pregnancies are also characterized by slightly elevated kynurenine/tryptophan, kynurenine/kynurenic acid, and kynurenine/quinolinic acid ratios (data not shown). The human placenta as well as the uterus express indolamine-2,3-dioxygenase 1 (IDO1), an enzyme that convert tryptophan to kynurenine, believed attenuate anti-fetal immune response. IDO1 activity increases gradually from the first to third trimester of pregnancy with an increase in kynurenine levels in placenta and uterus approximately eight-fold toward the end of the pregnancy [124]. Therefore, increased kynurenine levels could be an expression of higher activity of IDO1 in male pregnancies and/or by a coincidental difference in fetal gestational age.

While kynurenine and kynurenic acid is believed to have an anti-inflammatory activity, quinolinic acid has proinflammatory and cyto- and neurotoxic properties $[124,125]$. The presence of other neurotoxic substances in pregnancy $[13,18,67]$, as well as immune system activation $[15,18,19,44,45]$ are associated with a higher risk of ASD onset in offspring. Genetically predisposed male fetuses, being exposed for higher levels of neurotoxic substances such as quinolinic acid, may therefore run a higher risk of aberrant brain development compared to female fetuses. This difference between male and female pregnancies may partly explain the wellknown three-fold difference in prevalence of ASD diagnosis between men and women [126].

Maternal vitamin D status showed no associations with ASD onset in children contrary to recently published Australian, Chinese, and Swedish studies [29, 31, 32]. However, in the latter Swedish study, maternal vitamin D levels were not measured specifically during pregnancy but were collected from patient healthcare files [32]. The protocols of the Chinese and Australian studies $[29,31]$ were more comparable with our protocol with the exception that the majority of blood samples were from gestational week 14 in our study, and at gestational week 12 and 18 in the Chinese and Australian studies, respectively. Notably, in the large Australian cohort, there were no overall associations between child diagnosis and maternal vitamin D levels. An association could only be seen when special features of psychical development where considered [31]. We did not have the information about participants' social status, history of autoimmune disease, and psychiatric conditions in their families. All these factors may have strong impact on the likelihood of ASD occurrence in offspring [30-32] and failure to adjust for these parameters could have attenuated the expected associations between markers of inflammation and/or vitamin $\mathrm{D}$ in mothers blood and occurrence of ASD in children.

Two previous studies regarding connections between maternal CRP at mid-pregnancy (weeks 15-19) and risk of ASD in children [127, 128] showed opposite results. 
A statistically significant correlation between higher maternal CRP level and risk of ASD in children was found in a Finnish cohort [127], but in a comparable population from the USA, the correlation between maternal CRP and ASD in children was inversed [128]. These contradictory results were theorized to be caused by the genetic differences of the studied populations [128]. The results of our study showed no relation between maternal CRP and the occurrence of ASD in children. This may be related to a five to six times smaller amount of participants included in our work. In the American study, for example, there was also no correlation between maternal CRP and risk of ASD in children in the smallest of two subgroups [128].

The present blood specimens originated from the NSMK, a material originally collected for routine rubella serology testing. In the total cohort, gestational age ranged from 7 to 18 weeks. With respect to variations in menstrual cycle, duration of the follicular phase, and timing of conception, the fetal age may additionally vary by 3 weeks at the time of blood sampling [129]. Unfortunately, we do not have information about the exact time of collection of blood samples in our cohort, but variations in gestational age may have caused increased variability in our material and reduced the chances to find statistically significant associations between maternal CRP and/or vitamin D and occurrence of ASD in children.

Unlike other metabolites, high maternal folate status was positively associated with ASD occurrence in children. To the best of our knowledge, associations between maternal serum folate levels and ASD onset at this stage of pregnancy have not been reported before. Several previous studies have demonstrated an association of pre-, peri-, and postconceptional dietary folate intake with a decreased risk of ASD occurrence in offspring [35-39]. Folic acid supplementation in the first half of pregnancy was associated with decreased risk of ASD in children in USA [35], Norway [36], Canada [37], and Israel [38]. Contrary to the above mentioned, recent population-based studies in Denmark and Canada did not find any relationship between ASD risk and the use of folic acid supplementation by mothers between week -4 to +8 of pregnancy $[40,41]$.

It seems that maternal folate intake and risk of ASD in children may have more complicated relations. A Spanish study showed associations between decreased child psychomotor development and intake of more than 400 $\mu \mathrm{g}$ folic acid per day throughout pregnancy [42] and, very recently, in the Boston birth cohort, high folate and vitamin $B_{12}$ vitamin blood levels at birth were associated with an elevated risk of ASD in children [43]. The present study is based on a population not exposed to nutritional folic acid. In Sweden, food is generally not fortified with folic acid (in contrast to the USA, where blood folate levels are much higher due to food fortification). Dietary folate intake and prevalence of folic acid supplementation during pregnancy are known to be generally low in Sweden [130]. The vitamin concentrations observed in our material are below the levels that were reported in the Spanish and American studies. Therefore, different mechanisms may lay behind the association between folate status and ASD onset in the present study as compared to the abovementioned Spanish and Boston cohorts.

The information about vitamin supplementation in most of the abovementioned studies was obtained from food frequency questionnaires, pharmacy registers, or interviews. The present study does not use data about vitamin supplementation, but associates folate concentration in maternal serum with the occurrence of ASD in children. Serum folate levels may not be directly related to the amount of dietary folate intake. Previously elevated maternal whole blood folate levels during the first half of pregnancy were associated with a decreased risk of ASD in children of women with epilepsy [39], but an association between low whole blood folate levels and ASD risk for offspring of healthy mothers during the same period of pregnancy was not found [37]. In the same study, maternal folate supplementation during pregnancy was associated with a decreased ASD risk in children [37]. Therefore, the increased blood/serum folate levels may not be strictly related to dietary folate intake, but be a result of metabolic specificity.

The association of ASD risk with elevated circulating folate observed in our study may reflect altered activities of enzymes involved on folate-dependent one-carbon metabolism and/or impaired cobalamin function [131]. Thus, increased total folate in serum may be an epiphenomenon rather than the cause of ASD onset. This contention is supported by the results from a recent study reporting no association between maternal folic acid supplementation and occurrence of ASD in children [40, 41]. Another possible explanation could be disturbed folate uptake from blood into cells. Recently, ASD onset has been related to FR $\alpha$-autoantibodies, that seem to be prevalent in children with ASD and their relatives including their mothers [132-136]. Folate receptors alpha (FR )-autoantibodies prevent normal folate transport across the blood-brain barrier while normal content is observed in the blood [137] and may be a reason of folate insufficiency in cells with simultaneous high folate levels in blood.

In our study, unmetabolized folic acid was detected in a larger number of mothers in the case group compared to controls, suggesting that supplementation with folic acid around gestational week 14 was more common in mothers whose children later developed ASD. 
Folic acid taken as a supplement is rapidly converted to 5,10-methylenetetrahydrofolate (5,10-methlyTHF), and unmetabolized folic acid is not supposed to be found in serum in subjects taking less than $400 \mu \mathrm{g} /$ day [138]. Due to the limited sample size, the association did not reach statistical significance, but one may speculate if these women may have been using folic acid supplementation due to events in their medical history, such as unsuccessful attempts to become pregnant, earlier pregnancies with neural tube defects, or similar conditions that may have triggered folic acid supplementation. Considering recent findings confirming the notion of the complex role of folic acid in neurodevelopment [97], such as the direct correlation between extremely high maternal blood folate/folic acid supplementation and risk of ASD in children [42, 43], the correlation between extremely high blood levels of unmetabolized folic acid at birth, and elevated risk of developing food allergy in later life [94], the ability of folate to differentially alter the expression of genes associated with ASD onset [96], the relations between folic acid supplementation during pregnancy, and health of the offspring deserve further investigation.

Currently, we are not able to draw firm conclusions about potential pathomechanisms that could explain the associations between the higher folate levels in mothers and ASD onset, but the finding certainly deserves further exploration.

In the present study, in contrast to earlier research $[35,36,38,40-42]$, folate status around week 14 of pregnancy was not estimated from register data or food frequency questionnaires but measured in prediagnostic maternal blood samples. The samples were collected during the first routine midwife visit, which coincides with a period supposed to be critical for autism onset [13, 102]. Ideally, blood sampling should have occurred during earlier pregnancy phases, which better corresponds with recommendations for folic acid supplementation, that is the periconceptional period and the first trimester of pregnancy [38]. On the other hand, studying the associations between folic acid supplementation and ASD occurrence was not the primary aim of the present investigation. Furthermore, the blood folate level differences might not solely be explained by the amount of orally taken folic acid but rather by the particular qualities of the maternal folate metabolism [137, 139].

The feasibility of the stored material for biomarker analysis was unknown at the time we planned the study. As a consequence, the present investigation was designed as a pilot study to test the viability of the biobank material for determination of metabolic markers and we were only granted limited access to the serum biobank material (a maximum 100 cases and 100 controls). Moreover, the sample volume was restricted to $200 \mu \mathrm{L}$ by the biobank steering committee, and only samples with a remnant volume more than $700 \mu \mathrm{L}$ were eligible for our study. These restrictions explain the limited sample size and made duplicate analyses impossible. As a result, the present investigation has limited statistical power and does not allow for detection of small effect size associations. Furthermore, for the reasons given above, we did not have access to blood samples from all mothers who consented to participate in the study (Fig. 1). However, the proportion of missing blood samples was equal for both cases and controls. Therefore, a selection bias is unlikely. The only matching criterion between cases and controls was the child's year of birth, which further reduces the potential risk of bias and, in addition, the risk of group disparities due to storage artifacts. Indeed, pre-analytical variation due to non-optimal sample treatment and storage conditions are expected to attenuate rather than overestimate of the observed relationships. Some of the biomarkers, such as compounds of $\mathrm{B}_{6}$ vitamin group (for example PLP), are known to be unstable during long-term storage [113], and could not be detected in our material, while others were excluded from further statistical analysis due to results grossly deviating from expected concentration ranges based on reference material from other populations [104] (Additional file 4: Table S1). Still, the majority of biomarkers were within the expected concentration ranges and followed the expected seasonal variations $[105,122]$, which strengthen the validity of our analytical results. Finally, we cannot completely rule out differences in socio-demographic factors, nutritional status, and lifestyle habits between cases and controls, which may have confounded our results.

\section{Conclusion}

In the present study, we could not confirm postulated associations between ASD-risk in the offspring and maternal status of vitamin D, or markers of inflammation, but observed an unexpected difference in components of tryptophan metabolism in male and female pregnancies that may be linked to the 3:1 male-to-female prevalence typically found in ASD cohorts [126]. Opposed to our primary hypothesis that lower folate status may be associated with increased risk of ASD, we found weak evidence for an association between higher maternal folate status and occurrence of ASD in the offspring. Additional studies in larger cohorts utilizing optimally stored blood samples are warranted to elucidate the potential role of maternal folate status and folic acid supplementation during pregnancy in relation to ASD risk in the offspring. 


\section{Supplementary information}

Supplementary information accompanies this paper at https://doi.org/10. 1186/s13229-020-0315-z.

Additional file 1: Figure S1. Seasonal variations of studied biomarkers. The smooth line was fitted with locally weighted scatterplot smoothing (loess). a All participants. b Case group. c Control group.

Additional file 2: Figure S2. Associations between sampling year and studied biomarkers. The smooth line was fitted with loess. a All participants. b Case group. c Control group.

Additional file 3: Figure S3. Biomarker levels in each study participant, with a hierarchical cluster analysis based on Euclidian distances with complete linkage. Each column represents a participant and each row a biomarker. Heat map colors represent standardized log-transformed biomarker levels in all participants (red) and below mean biamarker levels (blue).

Additional file 4: Table S1. List of serum metabolites that were analyzed and used in further analysis. 'Only sum of THM and MTHM were included in the analysis as 'total folate'. ${ }^{2}$ The sums of the Asparagine and Aspartic acid and the f Glutamine and Glutamic acid levels were used in statistical analysis because of conversion between this forms in the stored samples. In the whole 45 biomarkers could be identified and included in the analysis.

Additional file 5: Table S2. Differences of biomarkers levels between mothers of children with infantile autism and Asperger's syndrome.

\section{Abbreviations}

ASD: Autism spectrum disorder; Cl: Confidence interval; CRP: C-reactive protein; DSM4: Diagnostic and statistical manual of mental disorders, 4-th edition; FDR: False discovery rate; FR1: Folate receptors subclass 1; FRs: Folate receptors; FRa: Folate receptors alpha; hmTHF: 4-Alfa-hydroxy-5-methyltetrahydrofolate; ICD: International statistical classification; KTR: Kynurenine/ tryptophan ratio; mTHF: 5-Methyl-tetrahydropholate;

MTHFR: Methylenetetrahydrofolate reductase; MTRR: Methionine synthase reductase; NSMC: Northern Sweden Maternity Cohort; OR: Odds ratio; SD: Standard deviation; tHcy: Total homocysteine

\section{Acknowledgments}

We thank all the participants for granting permission to use the blood serum samples in this study, biochemical laboratory Bevital for carrying out biochemical analyzes, and the University of Umeå for providing financial support.

\section{Authors' contributions}

OE made a substantial contribution to the conception and design of the work, acquisition and interpretation of the data, and writing of manuscript. RM made a substantial contribution to analysis, statistical interpretation of the data and writing of manuscript. JS made a substantial contribution to the works' design, interpretation of the data, and revised the manuscript. BH made a substantial contribution to the conception of the work and data acquisition, and revised the manuscript. SB made a substantial contribution to the conception of the work and revised the manuscript. ED made substantial contributions to the work concept, data interpretation, and revised the manuscript. BIA made a substantial contribution to the data acquisition and revised the manuscript. FE made substantial contributions to the acquisition, interpretation of the data, and revised the manuscript. PMU have substantively revised the work. S-AS made substantial contributions to the conception and design of the work, interpretation of the data, and drafted the work and revised it. All authors approved the submitted version.

\section{Funding}

This study was financially supported by Umeå University, Umeå, Sweden. Open access funding provided by Umea University.

\section{Availability of data and materials}

The datasets generated and analyzed during the current study are not publicly available due to private information they contain but are available from the corresponding author on reasonable request.

\section{Ethics approval and consent to participate}

The study was approved by the Regional Ethics Board at Umeå University, Umeå, Sweden, 2013-06-18, Dnr 2013-66-31M. Through an information letter, written informed consent was obtained, and mothers gave permission for using stored early pregnancy blood samples for the purpose of the present study, and for collecting registered information.

\section{Consent for publication}

Not applicable.

\section{Competing interests}

Sven Bölte declares no conflict of interest related to this article. Bölte discloses that he has in the last 5 years acted as an author, consultant, or lecturer for Shire, Medice, Roche, Eli Lilly, Prima Psychiatry, GLGroup, System Analytic, Kompetento, Expo Medica, and Prophase. He receives royalties for text books and diagnostic tools from Huber/Hogrefe, Kohlhammer and UTB. Erik Domellöf is supported by a grant from the Knut and Alice Wallenberg Foundation (KAW 2015.0192). There are no other financial disclosures or conflicts of interest.

\section{Author details}

${ }^{1}$ Department of Clinical Sciences, Pediatrics, Umeå University, Umeå, Sweden. ${ }^{2}$ Department of Radiation Sciences, Oncology, Umeå University, Umeå, Sweden. ${ }^{3}$ Department of Clinical Pharmacology, Pharmacology and Clinical Neurosciences, Umeå University, Umeå, Sweden. ${ }^{4}$ Department of Child and Adolescent Psychiatry, Umea University, Umeå, Sweden. ${ }^{5}$ Center of Neurodevelopmental Disorders (KIND), Centre for Psychiatry Research, Stockholm, Sweden. 'Department of Women's and Children's Health, Karolinska Institutet \& Child and Adolescent Psychiatry, Stockholm Health Care Services, Region Stockholm, Stockholm, Sweden. ${ }^{7}$ Curtin Autism Research Group, School of Occupational Therapy, Social Work and Speech Pathology, Curtin University, Perth, WA, Australia. ${ }^{8}$ Department of Psychology, Umeå University, Umeå, Sweden. ${ }^{9}$ Department of Clinical Microbiology, Umeå University, Umeå, Sweden. ${ }^{10}$ Bevital AS, Department of Clinical Science, University of Bergen, Bergen, Norway. ${ }^{11}$ Department of Medical Biochemistry and Pharmacology, Haukeland University Hospital, Bergen, Norway.

Received: 15 February 2019 Accepted: 2 January 2020

Published online: 16 January 2020

\section{References}

1. Diagnostic and Statistical Manual of Mental Disorders. Association AP, editor. Washington, DC, USA: American Psychiatric Association; 1994.

2. Lyall K, Croen L, Daniels J, Fallin MD, Ladd-Acosta C, Lee BK, et al. The changing epidemiology of autism spectrum disorders. Annu Rev Public Health. 2017;38:81-102.

3. Baio J, Wiggins L, Christensen DL, Maenner MJ, Daniels J, Warren Z, et al. Prevalence of autism spectrum disorder among children aged 8 years - autism and developmental disabilities monitoring network, 11 Sites, United States, 2014. Morbidity and mortality weekly report Surveillance summaries (Washington, DC : 2002). 2018;67(6):1-23.

4. Elsabbagh M, Divan G, Koh YJ, Kim YS, Kauchali S, Marcin C, et al. Global prevalence of autism and other pervasive developmental disorders. Autism Res. 2012;5(3):160-79.

5. Rutter M. Incidence of autism spectrum disorders: changes over time and their meaning. Acta Paediatr. 2005;94(1):2-15.

6. Ng M, de Montigny JG, Ofner M, Do MT. Environmental factors associated with autism spectrum disorder: a scoping review for the years 2003-2013. Health Promot Chronic Dis Prev Can. 2017;37(1):1-23.

7. Bolte S, Girdler S, Marschik PB. The contribution of environmental exposure to the etiology of autism spectrum disorder. Cell Mol Life Sci. 2019;76(7): 1275-97.

8. Gaugler T, Klei L, Sanders SJ, Bodea CA, Goldberg AP, Lee AB, et al. Most genetic risk for autism resides with common variation. Nat Genet. 2014; 46(8):881-5.

9. Talkowski ME, Minikel EV, Gusella JF. Autism spectrum disorder genetics: diverse genes with diverse clinical outcomes. Harv Rev Psychiatry. 2014. 22(2):65-75.

10. Herbert MR, Sage C. Autism and EMF? Plausibility of a pathophysiological link part II. Pathophysiology. 2013;20(3):211-34. 
11. Chaste P, Leboyer M. Autism risk factors: genes, environment, and geneenvironment interactions. Dialogues Clin Neurosci. 2012;14(3):281-92.

12. Gentile I, Zappulo E, Militerni R, Pascotto A, Borgia G, Bravaccio C. Etiopathogenesis of autism spectrum disorders: fitting the pieces of the puzzle together. Med Hypotheses. 2013;81(1):26-35.

13. King CR. A novel embryological theory of autism causation involving endogenous biochemicals capable of initiating cellular gene transcription: a possible link between twelve autism risk factors and the autism 'epidemic'. Med Hypotheses. 2011;76(5):653-60.

14. Li YM, Shen YD, Li YJ, Xun GL, Liu H, Wu RR, et al. Maternal dietary patterns, supplements intake and autism spectrum disorders: A preliminary casecontrol study. Medicine (Baltimore). 2018;97(52):e13902.

15. Machado CJ, Whitaker AM, Smith SE, Patterson PH, Bauman MD. Maternal immune activation in nonhuman primates alters social attention in juvenile offspring. Biol Psychiatry. 2015;77(9):823-32.

16. Straughen JK, Misra DP, Divine G, Shah R, Perez G, VanHorn S, et al. The association between placental histopathology and autism spectrum disorder. Placenta. 2017:57:183-8.

17. Lyall K, Munger KL, O'Reilly EJ, Santangelo SL, Ascherio A. Maternal dietary fat intake in association with autism spectrum disorders. Am J Epidemiol. 2013;178(2):209-20.

18. Patterson PH. Maternal infection and immune involvement in autism. Trends Mol Med. 2011;17(7):389-94.

19. Chen SW, Zhong XS, Jiang LN, Zheng XY, Xiong YQ, Ma SJ, et al. Maternal autoimmune diseases and the risk of autism spectrum disorders in offspring: A systematic review and meta-analysis. Behav Brain Res. 2016;296:61-9.

20. Kubota T, Miyake K, Hirasawa T. Epigenetic understanding of geneenvironment interactions in psychiatric disorders: a new concept of clinical genetics. Clin Epigenetics. 2012;4(1):1.

21. Gardner RM, Lee BK, Magnusson C, et al. Maternal body mass index during early pregnancy, gestational weight gain, and risk of autism spectrum disorders: Results from a Swedish total population and discordant sibling study. Int J Epidemiol. 2015;44(3):870-83. https://doi.org/10.1093/ije/dyv081.

22. Steenweg-de Graaff J, Tiemeier H, Ghassabian A, Rijlaarsdam J, Jaddoe WW, Verhulst FC, et al. Maternal fatty acid status during pregnancy and child autistic traits: the generation R study. Am J Epidemiol. 2016;183(9):792-9.

23. Julvez J, Mendez M, Fernandez-Barres S, Romaguera D, Vioque J, Llop S, et al. Maternal consumption of seafood in pregnancy and child neuropsychological development: a longitudinal study based on a population with high consumption levels. Am J Epidemiol. 2016;183(3):169-82.

24. Huizink AC, Mulder EJ. Maternal smoking, drinking or cannabis use during pregnancy and neurobehavioral and cognitive functioning in human offspring. Neurosci Biobehav Rev. 2006;30(1):24-41.

25. Grant WB, Cannell JJ. Autism prevalence in the United States with respect to solar UV-B doses: An ecological study. Dermatoendocrinol. 2013;5(1):159-64.

26. Dealberto MJ. Prevalence of autism according to maternal immigrant status and ethnic origin. Acta Psychiatr Scand. 2011;123(5):339-48.

27. Grant WB, Soles CM. Epidemiologic evidence supporting the role of maternal vitamin $D$ deficiency as a risk factor for the development of infantile autism. Dermatoendocrinol. 2009;1(4):223-8.

28. Fernell E, Barnevik-Olsson M, Bagenholm G, Gillberg C, Gustafsson S, Saaf M. Serum levels of 25-hydroxyvitamin D in mothers of Swedish and of Somali origin who have children with and without autism. Acta Paediatr. 2010;99(5):743-7.

29. Chen J, Xin K, Wei J, Zhang K, Xiao H. Lower maternal serum 25(OH) D in first trimester associated with higher autism risk in Chinese offspring. J Psychosom Res. 2016;89:98-101.

30. Whitehouse AJ, Holt BJ, Serralha M, Holt PG, Kusel MM, Hart PH. Maternal serum vitamin $D$ levels during pregnancy and offspring neurocognitive development. Pediatrics. 2012;129(3):485-93.

31. Whitehouse AJ, Holt BJ, Serralha M, Holt PG, Hart PH, Kusel MM. Maternal vitamin D levels and the autism phenotype among offspring. J Autism Dev Disord. 2013;43(7):1495-504.

32. Magnusson C, Lundberg M, Lee BK, Rai D, Karlsson H, Gardner R, et al. Maternal vitamin D deficiency and the risk of autism spectrum disorders: population-based study. BJPsych Open. 2016;2(2):170-2.

33. Fernell E, Mohamed AA, Martin H, Bagenholm G, Gillberg C. Children born to mothers of Somali origin with severe vitamin D deficiency during pregnancy - development at age 4 years. Acta Paediatr. 2015;104(4):428-9.

34. Fernell E, Bejerot S, Westerlund J, Miniscalco C, Simila H, Eyles D, et al. Autism spectrum disorder and low vitamin $D$ at birth: a sibling control study. Mol Autism. 2015;6:3.
35. Schmidt RJ, Tancredi DJ, Ozonoff S, Hansen RL, Hartiala J, Allayee H, et al. Maternal periconceptional folic acid intake and risk of autism spectrum disorders and developmental delay in the CHARGE (CHildhood Autism Risks from Genetics and Environment) case-control study. Am J Clin Nutr. 2012; 96(1):80-9.

36. Suren $P$, Roth $C$, Bresnahan M, Haugen M, Hornig M, Hirtz D, et al. Association between maternal use of folic acid supplements and risk of autism spectrum disorders in children. Jama. 2013;309(6):570-7.

37. Braun JM, Froehlich T, Kalkbrenner A, Pfeiffer CM, Fazili Z, Yolton K, et al. Brief report: are autistic-behaviors in children related to prenatal vitamin use and maternal whole blood folate concentrations? J Autism Dev Disord. 2014:44(10):2602-7.

38. Levine SZ, Kodesh A, Viktorin A, et al. Association of maternal use of folic acid and multivitamin supplements in the periods before and during pregnancy with the risk of autism spectrum disorder in offspring. JAMA Psychiatry. 2018;75(2):176-84. https://doi.org/10.1001/jamapsychiatry.2017. 4050

39. Bjork M, Riedel B, Spigset O, Veiby G, Kolstad E, Daltveit AK, et al. Association of folic acid supplementation during pregnancy with the risk of autistic traits in children exposed to antiepileptic drugs in utero. JAMA Neurol. 2018;75(2):160-8.

40. Virk J, Liew Z, Olsen J, Nohr EA, Catov JM, Ritz B. Preconceptional and prenatal supplementary folic acid and multivitamin intake and autism spectrum disorders. Autism. 2016;20(6):710-8.

41. Strom M, Granstrom C, Lyall K, Ascherio A, Olsen SF. Research Letter: Folic acid supplementation and intake of folate in pregnancy in relation to offspring risk of autism spectrum disorder. Psychol Med. 2018;48(6):1048-54.

42. Valera-Gran D, Garcia de la Hera M, Navarrete-Munoz EM, FernandezSomoano A, Tardon A, Julvez J, et al. Folic acid supplements during pregnancy and child psychomotor development after the first year of life. JAMA Pediatr. 2014;168(11):e142611.

43. Raghavan R, Riley AW, Volk H, Caruso D, Hironaka L, Sices L, et al. Maternal multivitamin intake, plasma folate and vitamin B12 levels and autism spectrum disorder risk in offspring. Paediatr Perinat Epidemiol. 2018;32(1):100-11.

44. Cannell JJ. Paracetamol, oxidative stress, vitamin D and autism spectrum disorders. Int J Epidemiol. 2014:43(3):974-5.

45. Brandlistuen RE, Ystrom E, Nulman I, Koren G, Nordeng H. Prenatal paracetamol exposure and child neurodevelopment: a sibling-controlled cohort study. Int J Epidemiol. 2013;42(6):1702-13.

46. Croen LA, Grether JK, Yoshida CK, Odouli R, Hendrick V. Antidepressant use during pregnancy and childhood autism spectrum disorders. Arch Gen Psychiatry. 2011;68(11):1104-12.

47. Ornoy A, Weinstein-Fudim L, Ergaz Z. Prenatal factors associated with autism spectrum disorder (ASD). Reprod Toxicol. 2015;56:155-69.

48. Bornehag CG, Lindh C, Reichenberg A, Wikstrom S, Unenge Hallerback M, Evans SF, et al. Association of Prenatal Phthalate Exposure With Language Development in Early Childhood. JAMA Pediatr. 2018;172(12):1169-76.

49. James SJ, Melnyk S, Jernigan S, Pavliv O, Trusty T, Lehman S, et al. A functional polymorphism in the reduced folate carrier gene and DNA hypomethylation in mothers of children with autism. Am J Med Genet B Neuropsychiatr Genet. 2010;153B(6):1209-20.

50. Adams M, Lucock M, Stuart J, Fardell S, Baker K, Ng X. Preliminary evidence for involvement of the folate gene polymorphism 19bp deletion-DHFR in occurrence of autism. Neurosci Lett. 2007;422(1):24-9.

51. Mohammad NS, Jain JM, Chintakindi KP, Singh RP, Naik U, Akella RR Aberrations in folate metabolic pathway and altered susceptibility to autism. Psychiatr Genet. 2009;19(4):171-6.

52. Shaik Mohammad N, Sai Shruti P, Bharathi V, Krishna Prasad C, Hussain T, Alrokayan SA, et al. Clinical utility of folate pathway genetic polymorphisms in the diagnosis of autism spectrum disorders. Psychiatr Genet. 2016;26(6):281-6.

53. Wang C, Geng H, Liu W, Zhang G. Prenatal, perinatal, and postnatal factors associated with autism: A meta-analysis. Medicine (Baltimore). 2017;96(18): e6696.

54. Gardener H, Spiegelman D, Buka SL. Prenatal risk factors for autism: comprehensive meta-analysis. Br J Psychiatry. 2009;195(1):7-14.

55. Li M, Francis E, Hinkle SN, Ajjarapu AS, Zhang C. Preconception and prenatal nutrition and neurodevelopmental disorders: a systematic review and metaanalysis. Nutrients. 2019;11(7):1628. Published 2019 Jul 17. https://doi.org/10. 3390/nu11071628.

56. Banik A, Kandilya D, Ramya S, Stünkel W, Chong YS, Dheen ST. Maternal factors that induce epigenetic changes contribute to neurological disorders 
in offspring. Genes (Basel). 2017;8(6):150. Published 2017 May 24. https://doi. org/10.3390/genes8060150.

57. Kocovska E, Fernell E, Billstedt E, Minnis H, Gillberg C. Vitamin D and autism: clinical review. Res Dev Disabil. 2012;33(5):1541-50.

58. Cannell JJ. On the aetiology of autism. Acta Paediatr. 2010;99(8):1128-30.

59. Cannell JJ, Grant WB. What is the role of vitamin D in autism? Dermatoendocrinol. 2013;5(1):199-204.

60. Kocovska E, Andorsdottir G, Weihe P, Halling J, Fernell E, Stora T, et al. Vitamin $d$ in the general population of young adults with autism in the faroe islands. J Autism Dev Disord. 2014;44(12):2996-3005.

61. Bener A, Khattab AO, Al-Dabbagh MM. Is high prevalence of vitamin D deficiency evidence for autism disorder?: In a highly endogamous population. J Pediatr Neurosci. 2014;9(3):227-33.

62. Mostafa GA, Al-Ayadhi LY. Reduced serum concentrations of 25-hydroxy vitamin $\mathrm{D}$ in children with autism: relation to autoimmunity. J Neuroinflammation. 2012;9:201

63. Jia F, Wang B, Shan L, Xu Z, Staal WG, Du L. Core symptoms of autism improved after vitamin D supplementation. Pediatrics. 2015;135(1):e196-8.

64. Saad K, Abdel-Rahman AA, Elserogy YM, et al. Vitamin D status in autism spectrum disorders and the efficacy of vitamin $D$ supplementation in autistic children. Nutr Neurosci. 2016;19(8):346-51. https://doi.org/10.1179/ $1476830515 Y .0000000019$.

65. Shalev H, Solt I, Chodick G. Month of birth and risk of autism spectrum disorder: a retrospective cohort of male children born in Israel. BMJ Open. 2017;7(11):e014606.

66. Eyles DW, Burne TH, McGrath JJ. Vitamin D, effects on brain development, adult brain function and the links between low levels of vitamin $D$ and neuropsychiatric disease. Front Neuroendocrinol. 2013;34(1):47-64.

67. Kern JK, Jones AM. Evidence of toxicity, oxidative stress, and neuronal insult in autism. J Toxicol Environ Health B Crit Rev. 2006;9(6):485-99.

68. Moore ME, Piazza A, McCartney Y, Lynch MA. Evidence that vitamin D3 reverses age-related inflammatory changes in the rat hippocampus. Biochem Soc Trans. 2005;33(Pt 4):573-7.

69. Garcion E, Wion-Barbot N, Montero-Menei CN, Berger F, Wion D. New clues about vitamin D functions in the nervous system. Trends Endocrinol Metab. 2002;13(3):100-5.

70. Burne TH, Feron F, Brown J, Eyles DW, McGrath JJ, Mackay-Sim A. Combined prenatal and chronic postnatal vitamin $\mathrm{D}$ deficiency in rats impairs prepulse inhibition of acoustic startle. Physiol Behav. 2004;81(4):651-5.

71. Masi A, Quintana DS, Glozier N, Lloyd AR, Hickie IB, Guastella AJ. Cytokine aberrations in autism spectrum disorder: a systematic review and metaanalysis. Mol Psychiatry. 2015;20(4):440-6.

72. Ashwood P, Van de Water J. A review of autism and the immune response. Clin Dev Immunol. 2004;11(2):165-74.

73. Jyonouchi H, Sun S, Le H. Proinflammatory and regulatory cytokine production associated with innate and adaptive immune responses in children with autism spectrum disorders and developmental regression. J Neuroimmunol. 2001;120(1-2):170-9.

74. Ashwood P, Krakowiak P, Hertz-Picciotto I, Hansen R, Pessah IN, Van de Water J. Altered T cell responses in children with autism. Brain Behav Immun. 2011;25(5):840-9.

75. Siniscalco D, Sapone A, Giordano C, Cirillo A, de Novellis V, de Magistris L, et al. The expression of caspases is enhanced in peripheral blood mononuclear cells of autism spectrum disorder patients. J Autism Dev Disord. 2012;42(7):1403-10.

76. Zimmerman AW, Jyonouchi H, Comi AM, Connors SL, Milstien S, Varsou A, et al. Cerebrospinal fluid and serum markers of inflammation in autism. Pediatr Neurol. 2005;33(3):195-201.

77. Laurence JA, Fatemi SH. Glial fibrillary acidic protein is elevated in superior frontal, parietal and cerebellar cortices of autistic subjects. Cerebellum. 2005;4(3):206-10.

78. Vargas DL, Nascimbene C, Krishnan C, Zimmerman AW, Pardo CA. Neuroglial activation and neuroinflammation in the brain of patients with autism. Ann Neurol. 2005;57(1):67-81.

79. Young AM, Campbell E, Lynch S, Suckling J, Powis SJ. Aberrant NF-kappaB expression in autism spectrum condition: a mechanism for neuroinflammation. Front Psychiatry. 2011;2:27.

80. Rodriguez JI, Kern JK. Evidence of microglial activation in autism and its possible role in brain underconnectivity. Neuron Glia Biol. 2011;7(2-4):205-13.

81. Gren A. Effects of vitamin E, C and D supplementation on inflammation and oxidative stress in streptozotocin-induced diabetic mice. Int I Vitam Nutr Res. 2013;83(3):168-75.
82. Barker T, Martins TB, Hill HR, Kjeldsberg CR, Dixon BM, Schneider ED, et al. Vitamin D sufficiency associates with an increase in antiinflammatory cytokines after intense exercise in humans. Cytokine. 2014; 65(2):134-7.

83. Scolletta S, Colletti M, Di Luigi L, Crescioli C. Vitamin D receptor agonists target CXCL10: new therapeutic tools for resolution of inflammation. Mediators Inflamm. 2013;2013:876319.

84. McDougle CJ, Landino SM, Vahabzadeh A, et al. Toward an immunemediated subtype of autism spectrum disorder. Brain Res. 2015;1617:72-92. https://doi.org/10.1016/j.brainres.2014.09.048.

85. Siniscalco D, Bradstreet JJ, Cirillo A, Antonucci N. The in vitro GcMAF effects on endocannabinoid system transcriptionomics, receptor formation, and cell activity of autism-derived macrophages. J Neuroinflammation. 2014;11:78.

86. Eyles DW, Liu PY, Josh P, Cui X. Intracellular distribution of the vitamin D receptor in the brain: comparison with classic target tissues and redistribution with development. Neuroscience. 2014;268:1-9.

87. Feron F, Burne TH, Brown J, Smith E, McGrath JJ, Mackay-Sim A, et al. Developmental vitamin D3 deficiency alters the adult rat brain. Brain Res Bull. 2005;65(2):141-8.

88. Almeras L, Eyles D, Benech P, Laffite D, Villard C, Patatian A, et al. Developmental vitamin $D$ deficiency alters brain protein expression in the adult rat: implications for neuropsychiatric disorders. Proteomics. 2007;7(5):769-80.

89. Viswanathan M, Treiman KA, Kish-Doto J, Middleton JC, Coker-Schwimmer EJ, Nicholson WK. Folic acid supplementation for the prevention of neural tube defects: an updated evidence report and systematic review for the US preventive services task force. Jama. 2017;317(2):190-203.

90. Balashova OA, Visina O, Borodinsky LN. Folate action in nervous system development and disease. Dev Neurobiol. 2018;78(4):391-402.

91. Araujo JR, Martel F, Borges N, Araujo JM, Keating E. Folates and aging: role in mild cognitive impairment, dementia and depression. Ageing Res Rev. 2015;22:9-19.

92. Vitvitsky V, Thomas M, Ghorpade A, Gendelman HE, Banerjee R. A functional transsulfuration pathway in the brain links to glutathione homeostasis. J Biol Chem. 2006;281(47):35785-93.

93. Dunstan JA, West C, McCarthy S, Metcalfe J, Meldrum S, Oddy WH, et al. The relationship between maternal folate status in pregnancy, cord blood folate levels, and allergic outcomes in early childhood. Allergy. 2012;67(1):50-7.

94. McGowan EC, Hong X, Selhub J, et al. Association Between Folate Metabolites and the Development of Food Allergy in Children [published online ahead of print, 2019 Jun 25]. J Allergy Clin Immunol Pract. 2019; S2213-2198(19)30569-0. https://doi.org/10.1016/j.jaip.2019.06.017.

95. Boshnjaku V, Shim KW, Tsurubuchi T, Ichi S, Szany EV, Xi G, et al. Nuclear localization of folate receptor alpha: a new role as a transcription factor. Sci Rep. 2012;2:980.

96. Barua S, Kuizon S, Ted Brown W, Junaid MA. High gestational folic acid supplementation alters expression of imprinted and candidate autism susceptibility genes in a sex-Specific Manner in Mouse Offspring. J Mol Neurosci. 2016;58(2):277-86.

97. Rogers EJ. Has enhanced folate status during pregnancy altered natural selection and possibly Autism prevalence? A closer look at a possible link. Med Hypotheses. 2008;71(3):406-10.

98. DeVilbiss EA, Gardner RM, Newschaffer CJ, Lee BK. Maternal folate status as a risk factor for autism spectrum disorders: a review of existing evidence. $\mathrm{Br}$ J Nutr. 2015;114(5):663-72.

99. Mohammad-Rezazadeh I, Frohlich J, Loo SK, Jeste SS. Brain connectivity in autism spectrum disorder. Curr Opin Neurol. 2016;29(2):137-47.

100. Ecker C. The neuroanatomy of autism spectrum disorder: an overview of structural neuroimaging findings and their translatability to the clinical setting. Autism. 2017;21(1):18-28.

101. Stiles J, Jernigan TL. The basics of brain development. Neuropsychol Rev. 2010;20(4):327-48.

102. Marin O. Developmental timing and critical windows for the treatment of psychiatric disorders. Nat Med. 2016;22(11):1229-38.

103. Lukanova A, Toniolo P, Zeleniuch-Jacquotte A, Grankvist K, Wulff M, Arslan $A A$, et al. Insulin-like growth factor I in pregnancy and maternal risk of breast cancer. Cancer Epidemiol Biomarkers Prev. 2006;15(12): 2489-93.

104. Pukkala E, Andersen A, Berglund G, Gislefoss R, Gudnason V, Hallmans G, et al. Nordic biological specimen banks as basis for studies of cancer causes and control--more than 2 million sample donors, 25 million person years and 100,000 prospective cancers. Acta Oncol. 2007;46(3):286-307. 
105. Assessement of heals status by metabolic markers [Web page]. http://www. bevital.no/ Bevital, Department of Clinical Science, Bergen,Norway; 2017 [updated May 6, 2018; cited 2016 December 16].

106. Hannisdal R, Ueland PM, Svardal A. Liquid chromatography-tandem mass spectrometry analysis of folate and folate catabolites in human serum. Clin Chem. 2009:55(6):1147-54.

107. Midttun O, Kvalheim G, Ueland PM. High-throughput, low-volume, multianalyte quantification of plasma metabolites related to one-carbon metabolism using HPLC-MS/MS. Anal Bioanal Chem. 2013;405(6):2009-17.

108. Midttun O, McCann A, Aarseth O, Krokeide M, Kvalheim G, Meyer K, et al. Combined measurement of 6 fat-soluble vitamins and 26 water-soluble functional vitamin markers and Amino acids in $50 \mathrm{~mL}$ of serum or plasma by high-throughput mass spectrometry. Anal Chem. 2016;88(21):10427-36.

109. Meyer K, Ueland PM. Targeted quantification of C-reactive protein and cystatin C and its variants by immuno-MALDI-MS. Anal Chem. 2014;86(12): 5807-14.

110. Molloy AM, Scott JM. Microbiological assay for serum, plasma, and red cell folate using cryopreserved, microtiter plate method. Methods Enzymol. 1997;281:43-53.

111. Hannisdal R, Gislefoss RE, Grimsrud TK, Hustad S, Morkrid L, Ueland PM. Analytical recovery of folate and its degradation products in human serum stored at -25 degrees C for up to 29 years. J Nutr. 2010;140(3):522-6.

112. Midttun O, Townsend MK, Nygard O, Tworoger SS, Brennan P, Johansson M, et al. Most blood biomarkers related to vitamin status, one-carbon metabolism, and the kynurenine pathway show adequate preanalytical stability and within-person reproducibility to allow assessment of exposure or nutritional status in healthy women and cardiovascular patients. J Nutr. 2014;144(5):784-90.

113. Hustad S, Eussen S, Midttun O, Ulvik A, van de Kant PM, Morkrid L, et al. Kinetic modeling of storage effects on biomarkers related to $B$ vitamin status and one-carbon metabolism. Clin Chem. 2012;58(2):402-10.

114. Takehana S, Yoshida H, Ozawa S, Yamazaki J, Shimbo K, Nakayama A, et al. The effects of pre-analysis sample handling on human plasma amino acid concentrations. Clin Chim Acta. 2016:455:68-74.

115. Midttun O, Hustad S, Ueland PM. Quantitative profiling of biomarkers related to B-vitamin status, tryptophan metabolism and inflammation in human plasma by liquid chromatography/tandem mass spectrometry. Rapid Commun Mass Spectrom. 2009:23(9):1371-9.

116. St Helen G, Novalen M, Heitjan DF, Dempsey D, Jacob P 3rd, Aziziyeh A, et al. Reproducibility of the nicotine metabolite ratio in cigarette smokers. Cancer Epidemiol Biomarkers Prev. 2012;21(7):1105-14.

117. Abdallah IA, Hammell DC, Stinchcomb AL, Hassan HE. A fully validated LCMS/MS method for simultaneous determination of nicotine and its metabolite cotinine in human serum and its application to a pharmacokinetic study after using nicotine transdermal delivery systems with standard heat application in adult smokers. J Chromatogr B Analyt Technol Biomed Life Sci. 2016;1020:67-77.

118. Ueland PM, McCann A, Midttun O, Ulvik A. Inflammation, vitamin B6 and related pathways. Mol Aspects Med. 2017;53:10-27.

119. Benjamini $Y$, Hochberg $Y$. Controlling the false discovery rate: a practical and powerful approach to multiple testing. Journal of the Royal Statistical Society Series B (Methodological). 1995;57(1):289-300.

120. Scutari M, Nagarajan R. Identifying significant edges in graphical models of molecular networks. Artif Intell Med. 2013;57(3):207-17.

121. Scutari M. Learning Bayesian Networks with the bnlearn R Package. J Stat Software. 2010;35(3). https://www.jstatsoft.org/v035/i03.

122. Klingberg E, Olerod G, Konar J, Petzold M, Hammarsten O. Seasonal variations in serum 25-hydroxy vitamin D levels in a Swedish cohort. Endocrine. 2015:49(3):800-8.

123. Liu H, Ding L, Zhang H, Mellor D, Wu H, Zhao D, et al. The metabolic factor kynurenic acid of kynurenine pathway predicts major depressive disorder. Front Psychiatry. 2018;9:552.

124. Blaschitz A, Gauster M, Fuchs D, Lang I, Maschke P, Ulrich D, et al. Vascular endothelial expression of indoleamine 2,3-dioxygenase 1 forms a positive gradient towards the feto-maternal interface. PLoS One. 2011;6(7):e21774.

125. Dantzer R. Role of the kynurenine metabolism pathway in inflammationinduced depression: preclinical approaches. Curr Top Behav Neurosci. 2017; 31:117-38.

126. Loomes R, Hull L, Mandy WPL. What is the male-to-female ratio in autism spectrum disorder? A systematic review and meta-analysis. J Am Acad Child Adolesc Psychiatry. 2017;56(6):466-74.
127. Brown AS, Sourander A, Hinkka-Yli-Salomäki S, McKeague IW, Sundvall J, Surcel HM. Elevated maternal C-reactive protein and autism in a national birth cohort. Molecular psychiatry. 2014;19(2):259-64.

128. Zerbo O, Traglia M, Yoshida C, Heuer LS, Ashwood P, Delorenze GN, et al. Maternal mid-pregnancy C-reactive protein and risk of autism spectrum disorders: the early markers for autism study. Transl Psychiatry. 2016;6(4): e783-e.

129. Bull JR, Rowland SP, Scherwitzl EB, Scherwitzl R, Danielsson KG, Harper J. Real-world menstrual cycle characteristics of more than 600,000 menstrual cycles. NPJ Digit Med. 2019;2:83.

130. Murto T, Yngve A, Skoog Svanberg A, Altmäe S, Salumets A, Wånggren K, et al. Compliance to the recommended use of folic acid supplements for women in Sweden is higher among those under treatment for infertility than among fertile controls and is also related to socioeconomic status and lifestyle. Food Nutr Res. 2017:61(1):1334483.

131. Paul L, Selhub J. Interaction between excess folate and low vitamin B12 status. Mol Aspects Med. 2017:53:43-7.

132. Ramaekers VT, Blau N, Sequeira JM, Nassogne MC, Quadros EV. Folate receptor autoimmunity and cerebral folate deficiency in low-functioning autism with neurological deficits. Neuropediatrics. 2007;38(6):276-81.

133. Ramaekers VT, Quadros EV, Sequeira JM. Role of folate receptor autoantibodies in infantile autism. Molecular psychiatry. 2013;18(3):270-1.

134. Frye RE, Sequeira JM, Quadros EV, James SJ, Rossignol DA. Cerebral folate receptor autoantibodies in autism spectrum disorder. Mol Psychiatry. 2013; 18(3):369-81.

135. Quadros EV, Sequeira JM, Brown WT, Mevs C, Marchi E, Flory M, et al. Folate receptor autoantibodies are prevalent in children diagnosed with autism spectrum disorder, their normal siblings and parents. Autism Res. 2018;11(5): 707-12.

136. Ramaekers VT, Sequeira JM, DiDuca M, Vrancken G, Thomas A, Philippe C, et al. Improving outcome in infantile autism with folate receptor autoimmunity and nutritional derangements: a self-controlled trial. Autism Res Treat. 2019;2019:7486431.

137. Ramaekers VT, Rothenberg SP, Sequeira JM, Opladen T, Blau N, Quadros EV, et al. Autoantibodies to folate receptors in the cerebral folate deficiency syndrome. N Engl J Med. 2005;352(19):1985-91.

138. Kelly P, McPartlin J, Goggins M, Weir DG, Scott JM. Unmetabolized folic acid in serum: acute studies in subjects consuming fortified food and supplements. Am J Clin Nutr. 1997;65(6):1790-5.

139. Guinotte $C L$, Burns MG, Axume JA, Hata H, Urrutia TF, Alamilla A, et al. Methylenetetrahydrofolate reductase $677 \mathrm{C}-->$ T variant modulates folate status response to controlled folate intakes in young women. J Nutr. 2003; 133(5):1272-80.

\section{Publisher's Note}

Springer Nature remains neutral with regard to jurisdictional claims in published maps and institutional affiliations.

Ready to submit your research? Choose BMC and benefit from:

- fast, convenient online submission

- thorough peer review by experienced researchers in your field

- rapid publication on acceptance

- support for research data, including large and complex data types

- gold Open Access which fosters wider collaboration and increased citations

- maximum visibility for your research: over $100 \mathrm{M}$ website views per year

At $\mathrm{BMC}$, research is always in progress.

Learn more biomedcentral.com/submission 